\title{
Wenn das Gras den Viechern direkt ins Maul wächst*
}

Peter Marko

* Hanny Zeller, Altgemeindeschwester in Zweisimmen, gewidmet.
Jedes Jahr gegen Ende des Winters bekam er eine Lungenentzündung. Damals existierte noch keine Impfung dagegen. Die ersten zwei, drei Tage spritzte ich ihm ein Antibiotikum und als es ihm besser ging, was immer der Fall war, verabreichte ihm die Frau die Tabletten. Sie tat es sehr gewissenhaft. Ab und zu sah ich sie beide vor allem an «Märittagen» im Dorf. Er trug immer eine braune Filzhose und dieselbe Jacke, sie ein altmodisches Kleid mit einem kleinblumigen Muster und eine Schürze. Ihr Mund hatte grosse Zahnlücken, was sie überhaupt nicht hinderte, herzlich zu lachen. Eine Zahnversorgung war für sie offensichtlich unüblich, unnatürlich, überflüssig. Er liess sich nie in der Praxis blicken.

In ihrem etwas abgelegenen alten Holzhaus wärmten sie das Wasser und kochten mit Holz auf einem Herd. Vermutlich gab es nur ein Plumpsklo. Als ich kam, sass er jeweils schon in der warmen Küche. Der Weg dorthin führte über einen Gang, eine Art von Veranda, in dem man sich durch Haufen von Altpapier, leeren Flaschen, volle Taschen und andere gebrauchte Gegenstände durchschlängeln musste. Dazu gehörten Schalen mit Fressresten für mehrere Katzen, die einen je nach Laune mehr oder weniger freundlich begrüssten. Man musste darauf achten, dass man ihnen die Pfoten bei dem Hindernislauf nicht zerdrückte. Wie sah es wohl in den anderen Räumen des Hauses aus?

Arm waren sie nicht. Ausser der riesigen Wiese mit dem Haus gehörten ihnen noch andere rund ums Dorf und sogar ein «Berg», eine Alp. Sie besassen nicht viele Tiere und so haben sie ihr Reich mehrheitlich verpachtet. Sie arbeiteten aus Pflicht, Gewohnheit und Spass, desto mehr weil sie kinderlos blieben. Als er älter und schwächer wurde, verzichteten sie ganz auf das «Bauern». Sie half dann in der Küche eines Restaurants aus.

Eines Tages klagte er, dass er nicht gut Urin lösen könne. Sowohl der Tastbefund wie das Labor zeigten einen fortgeschrittenen Prostatakrebs. Als ich einmal im Mai an meinem freien Nachmittag den Katheter gewechselt hatte, begleitete sie mich ein Stück zum Auto. Auch sie war froh, aus dem dunklen Haus an die frische Luft hinauszukommen. Die Sonne schien, die
Wiese blühte, die Kühe lechzten nach dem Gras und dem Wasser aus dem Trog, in den es aus dem Brunnen plätscherte, man hörte ihr lautes Schnaufen und ihre Glocken. Wir blickten von oben auf das Dorf und weit ins Tal. Die Spitzen der Berge waren noch weiss vom Restschnee. Ich sagte, es scheint ein gutes Jahr zu werden. Sie sagte dazu in ihrem singenden Dialekt: Ja, das Gras wächst den Viechern direkt ins Maul. Treffender konnte man das Ganze nicht ausdrücken.

Eine Untersuchung und Beurteilung bei einem Spezialisten, eine Einweisung ins Spital, eine Operation oder Bestrahlung wären für ihn unüblich, unnatürlich, überflüssig, eine $\mathrm{Zu}$ mutung und kamen nicht in Frage. Und so starb er in seinem Haus, man kann sagen glücklich und zufrieden, so wie er dort gelebt hatte, sorgsam und liebevoll gepflegt von der Frau und der Gemeindeschwester.

Schon als Kind störte mich, dass ich aus Kleidern, die ich gerne trug, hinauswuchs. Ungefähr zweijährig besass ich einen Overall, damals eine Seltenheit, in dem ich mich wie ein Pilot oder Rennfahrer vorkam, deren Berufe ich gerne in meinem Holzauto spielte. Ich konnte meiner Mutter nicht verzeihen, dass ich den Anzug nur ein bis zweimal tragen durfte, da sie ihn nur für besondere Gelegenheiten aufhob. Damals hatte man noch Kleider, die man nur an Sonn- und Feiertagen anziehen durfte beziehungsweise musste. Später war das Neue für mich wichtig und interessant. Seit geraumer Zeit trenne ich mich wieder besonders schwer von Sachen und Gegenständen, die ich gern habe, die mir gut dienten, mit und in denen ich viel erlebte. Es braucht eine äussere Kraft oder Macht, die mich dazu zwingt. Dann suche ich eine gute Gelegenheit, mich davon zu lösen. Und so sammeln sich in der Warteschleife im Schrank Hemden, Jacken und Hosen, die das letzte Mal gewaschen wurden. Ihre Zahl übersteigt langsam die derjenigen, die ich noch unbeschränkt tragen darf. Das 1.-AugustFest auf einer Alp mit Höhenfeuer war ein würdiger Anlass, mich von Turnschuhen zu verabschieden, in denen ich jahrelang wanderte, besser gesagt, über Feld, Wiese, durch Wald, Wasser, Schilf und Farn schwebte, ohne Blasen 
und Schwielen, aber die Löcher im Futter an der Ferse begannen leider die Socken kaputtzumachen. Während Menschen und Tiere von uns gehen, ohne dass wir es gross beeinflussen können, entscheiden wir, wann und wie wir uns von Sachen endgültig trennen. Es ist eine Art von Mord oder Selbstmord, da damit ein handfestes Stück unserer Erinnerung, ein Stück von uns selbst verschwindet.

Schon immer hatte ich gerne Kleider, die mehreren Zwecken dienen konnten, wie reversible Jacken. Jetzt besitze ich immer weniger Kleidungsstücke, aber immer mehr solche von «universeller» Art. Mit schwerem Herzen werde ich mich einmal von meinen Schuhen trennen, in denen ich sowohl wandere wie ins Theater gehe, von der Jacke, in der ich Ski fahre und den ganzen Winter in der Stadt trage. Ist die nicht nachlassende Beliebtheit der Jeans auch ein Zeichen dieser Sehnsucht nach Einfachem, Gleichem? Wie leicht hatte es mein Patient mit seiner Garderobe, seinen braunen Filzhosen und seinem geblümten hellblauen Hemd, die man an jedem «Märit» kaufen kann. Gefällt mir ein blaues Hemd, muss ich mir gleich mehrere Stücke besorgen, weil Jahre vergehen, bis blau wieder Mode wird, dann aber während einer Saison lauter blaue Hemden in den Geschäften auftauchen.

Ja, wenn es mir so durch den Kopf geht, denke ich, dass es kaum Zufall war, dass ich in «säbem» Haus der Arzt war.

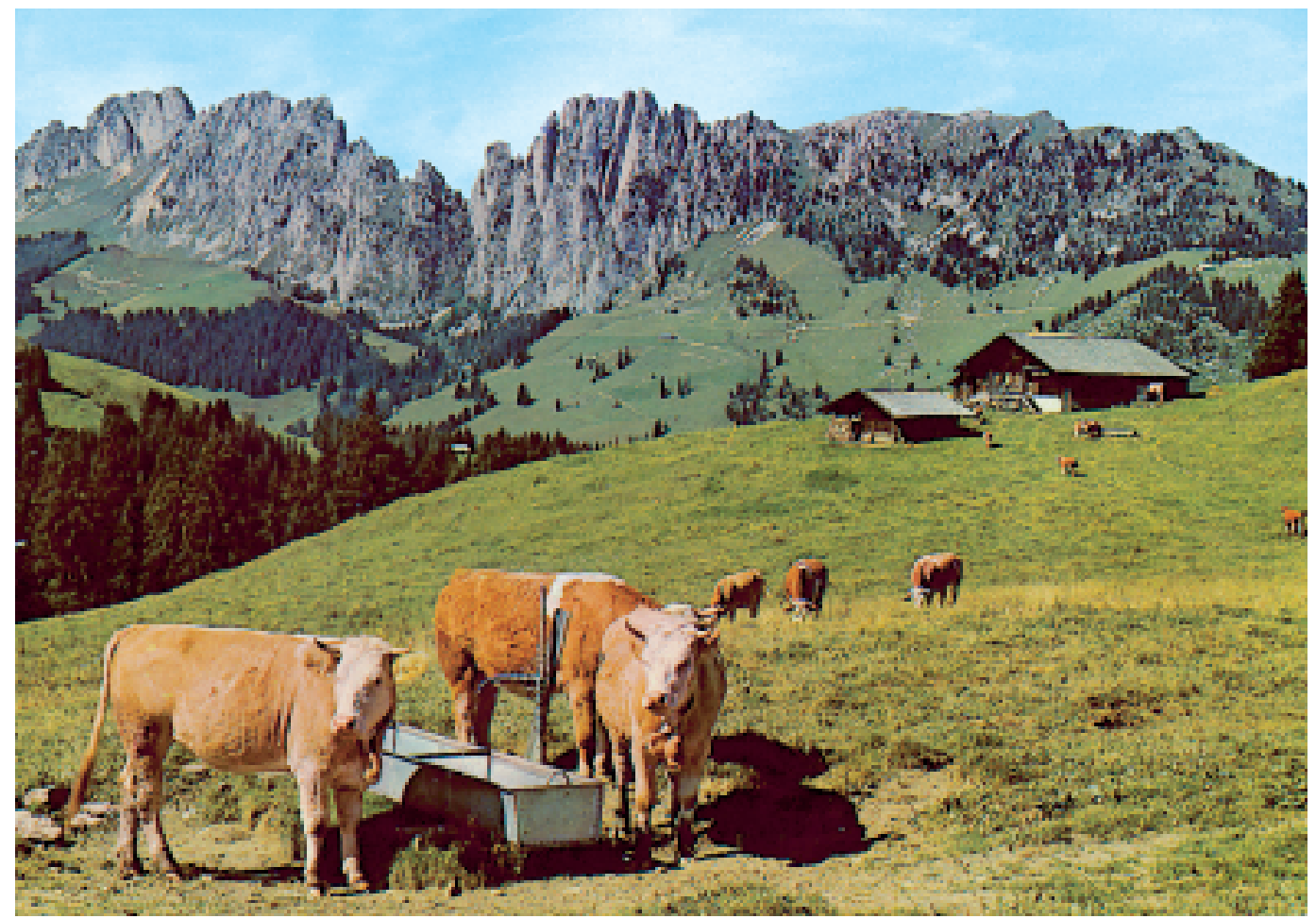

Gygerphoto, Adelboden 